\title{
Patients' Experiences of Trust in the Patient-Nurse Relationship-A Systematic Review of Qualitative Studies
}

\author{
Kristine Rørtveit ${ }^{*}$, Britt Sætre Hansen², Ingrid Leiknes³, Inge Joa4, \\ Ingelin Testad ${ }^{5}$, Elisabeth Severinsson ${ }^{6}$ \\ ${ }^{1}$ Stavanger University Hospital, Stavanger, Norway \\ ${ }^{2}$ Department of Health Studies, Faculty of Social Sciences, University of Stavanger, Stavanger, Norway \\ ${ }^{3}$ Centre for Movement Disorders, Stavanger University Hospital, Stavanger, Norway \\ ${ }^{4}$ Division of Psychiatry, Regional Centre for Clinical Research in Psychosis, Stavanger University Hospital, \\ Stavanger, Norway \\ ${ }^{5}$ Regional Centre for Age-Related Medicine (SESAM), Stavanger University Hospital, Stavanger, Norway \\ ${ }^{6}$ Department of Research, Stavanger University Hospital, Stavanger, Norway \\ Email: ${ }^{*}$ kristine.rortveit@sus.no
}

Received 27 February 2015; accepted 15 March 2015; published 20 March 2015

Copyright (C) 2015 by authors and Scientific Research Publishing Inc.

This work is licensed under the Creative Commons Attribution International License (CC BY).

http://creativecommons.org/licenses/by/4.0/

(c) (;) Open Access

\section{Abstract}

Aims and Objectives: To report a synthesis of the literature on the meaning of trust in the context of patients' experiences of nursing. The review question was "How do patients describe the meaning of trust in the nursing relationship?" Background: Trust is essential in nursing as it has the potential to create opportunities for the human being to gain faith, hope and meaning in life as well as open up for new experiences. Trust is an interpersonal and essential element of all patient-nurse relationships and requires nurses to create a trusting relationship with the patients. Design: Systematic qualitative literature review. Methods: Systematic searches were conducted for the period January 2002 to December 2012, updated in January 2014. 20 papers were included. Results: Four categories emerged: Attitudes related to trust, indicating that trust is fundamental and existential; Experiences of trust, concerning how trust can be sensed; The patient-nurse relationship, revealing the qualities of the person who creates trust; and Where trust occurs, illuminating the contextual relevancies of trust. Conclusions: Patients' experiences of trust in nursing are dependent on the nurses' knowledge, level of commitment in the dialogue to creating and developing the relationship and contextual issues. Implications for nursing practice: Reflection on a trusting relationship with the patient is necessary for a deeper conceptual understanding of trust in nursing. Clinical nurse researchers nurse supervisors, managers and nurse educatorsshould discuss different areas of trust during nursing supervision and focus-group meetings as well as with nursing graduates to ensure that nurses develop knowledge of how to create a trusting patient-nurse relationship.

\footnotetext{
"Corresponding author.
}

How to cite this paper: Rørtveit, K., Hansen, B.S., Leiknes, I., Joa, I., Testad, I. and Severinsson, E. (2015) Patients' Experiences of Trust in the Patient-Nurse Relationship-A Systematic Review of Qualitative Studies. Open Journal of Nursing, 5, 195-209. http://dx.doi.org/10.4236/ojn.2015.53024 


\section{Keywords}

\section{Patient-Nurse Relationship, Patient Experience, Qualitative Literature Review, Trust}

\section{Introduction}

Trust is essential in the relationship between the healthcare professional and patient [1]-[3]. Trust as an interpersonal and essential element of all patient-nurse relationships was the clearest result in a literature review of trust and trustworthiness. Trust was viewed as a dynamic process evolving over time where reliance on others, risk and fragility were identified as basic attributes [4]. Trust between patient and nurse is essential for reducing patients' anxiety, and enabling them to regain a sense of control [5]. Caring is based on relationships and an ethical stance that have to be learned in everyday practice. By her/his actions and practical competence, the nurse demonstrates a standard for care that allows the patient to trust her/him [6]. The phenomenon of trust is related to power and present in all caring contexts; it has an impact on whether the patients' directions expands or restricts [7]. When vulnerable patients are unable to meet their own needs, they must trust in the good will of nurses, who often interact intimately in their lives [8].

There are many definitions of trust [9]; as both a process and an outcome in clinical and organisational contexts [10], between families and professionals [11], as well as in interdisciplinary literature [12]. Previous literature has pointed out four key features of trust: What it is, why it matters, on what it is based, and the danger of trust, concluding that management is important for generating trust in the healthcare system [13]. One literature review discuss four factors that influence patient trust; 1) potential for shame and humiliation, 2) the power imbalance in the relationship, 3) failure of understanding of how the patient is suffering from the illness and 4) failure of understanding of the patients' suffering due to the treatment [1]. The results reveal that patients are best cared for in a setting where disease is understood, medical problems treated and that the patient is accompanied through the illness experience. Such a setting requires an appreciation of the challenges to the experience of trust resulting from the special characteristics of the patient-nurse relationship.

Trust has the potential to create opportunities for the human being to gain faith, hope and meaning in life as well as open up for new experiences [14]. When a person trusts another person it means opening up for an action and expecting the other (trustor) to act in accordance with his/her (trustee's) wishes, interests or will. Trust is often defined as the opposite of power. Trust, choice and power are important areas in mental healthcare as patients expect to participate in the treatment process. The power issue between patients and nurses can cause some patients not to avail of healthcare services [15]. One study explored the limitations of communication theory by considering the different perspectives of researchers, clinicians, patients and teachers, revealing that researchers focus on communication mechanics and techniques while "patients seek relationships in which they experience trust, the right amount of autonomy, caring and expertise” (p. 272). They argue that nurse educators and leaders should ensure that nurses develop attitudes and knowledge as a basis for the creation of a trusting patient-nurse relationship. Reflection on the conceptual understanding of trust in nursing is essential [16].

Trust is an important aspect of nursing and has been the focus of nursing theory and research. There is a need for theoretical research on trust in nursing with an international perspective. A synthesis of available evidence might provide a starting point. A concept analysis of trust provides a greater understanding of its role in the patient-nurse relationship [17]. However, there is a gap in the understanding of the meaning patients attribute to trust and how the development of trust should be facilitated based on empirical studies [18]. The large body of literature on trust within nursing lacks depth, research evidence and focuses on the potential benefits of a patient-nurse relationship [12]. The present review was conducted to contribute a deeper clinical understanding of patient-oriented phenomena in order to enhance nursing care [19], by means of a synthesis of available qualitative evidence of patients' experiences of trust and its meaning in nursing.

\section{Aim}

The aim of this review was to report a synthesis of the literature on the meaning of trust in the context of patients' experiences of nursing. The review question was "How do patients describe the meaning of trust in the nursing relationship”? 


\section{Methods}

A systematic review was performed [20] on qualitative evidence to expand knowledge of the meaning of trust from the patient perspective, thus allowing a more exploratory and substantive approach to the phenomenon [21] [22]. The authors are six nurse researchers working in different clinical settings (intensive care, psychiatric care, movement disorders, dementia, geriatric care and the research department) at a University hospital on the West coast of Norway.

A thematic data-driven analysis was performed and the findings of different studies were summarised under thematic headings. The analysis was performed in steps, the first of which involved identifying themes from the findings of each study after which we sorted the themes by summarizing the main point and organising them into categories. Finally, we developed the descriptive themes by discussing, naming and comparing them in order to ensure that they were robust. The process was carried out bearing the review question in mind [20] [23]. Codes were referred to as meaning units, categories as a group of content with shared commonality and themes as the "thread of underlying meaning" (p. 107) [23]. Patient trust was reflected on and discussed in relation to the aim of the study.

\subsection{Inclusion Criteria}

The inclusion criteria were: the patients' perspective of the patient-nurse relationship, trust as an outcome, qualitative studies, English language, last 10 years:

\subsection{Search Strategy}

A search was made in the PubMed, CINAHL, PsycINFO and Embase databases covering the period January 2002 to December 2012, updated in January 2014 using nurs ${ }^{*}$ AND patient trust ${ }^{*}$ AND experience* The search strategies were designed in collaboration with experts from the University Hospital library. In addition, the reference lists of the selected papers were screened. A later search in PubMed was also performed covering the period December 2012 to January 2014but no papers met the inclusion criteria.

A total of (954) abstracts were read. A qualitative method filter was employed when searching the Psychinfo (85), CINAHL (121) and Embase (161) databases. During the search, three of the authors read the abstracts of the 806 articles retrieved from PubMed, and from all the databases, 23 met the inclusion criteria. Three were excluded due to lack of focus on the patient-nurse relationship (Figure 1). The results were structured by theme as in a thematic analysis [20] [23]. Four categories and eight sub-categories were formulated.

\subsection{Assessment of Methodological Quality}

\subsubsection{Data Abstraction and Assessment of Methodological Quality}

The methodological quality of the included papers was assessed and rated according to the Critical Appraisal Skills Program (CASP), a methodological checklist of key criteria relevant to qualitative studies [24]. The three authors (KR/IL/BSH) independently assessed the quality of the studies. Agreement was reached by re-reading and discussing the studies in the light of the various criteria. The three researchers reached a final decision of low methodological quality for three, moderate for 10 and high for seven of the 20 studies. No paper was excluded. The final assessment and example is presented in Appendix 1 and Appendix 2.

Studies describing patients' experiences of trust involving the patient-nurse relationship were included.

\subsubsection{Different Methodological and Analytical Approaches in the Reviewed Studies}

The included papers employed different qualitative approaches such as ethnographic, interpretative phenomenological, interpretative descriptive, reflexive inquiry and Grounded Theory. Data were collected from participant observations as well as the following types of interview; in-depth semi-structured video-recorded, ethnographic, grounded theory, conversational, narrative, telephone, open-ended structured, semi-structured and unstructured in addition to discussions.

Different analysis methods were employed in the papers; interpretative phenomenological, grounded theory, narrative, the NVivo computer program, textual, qualitative content, qualitative inductive, thematic, hermeneutic, systematic, the phenomenological processes of immersion, incubation, illumination, explication and creative analysis, Van Mannens’ phenomenology approach and the NUD*ST ATLAS computer program. 


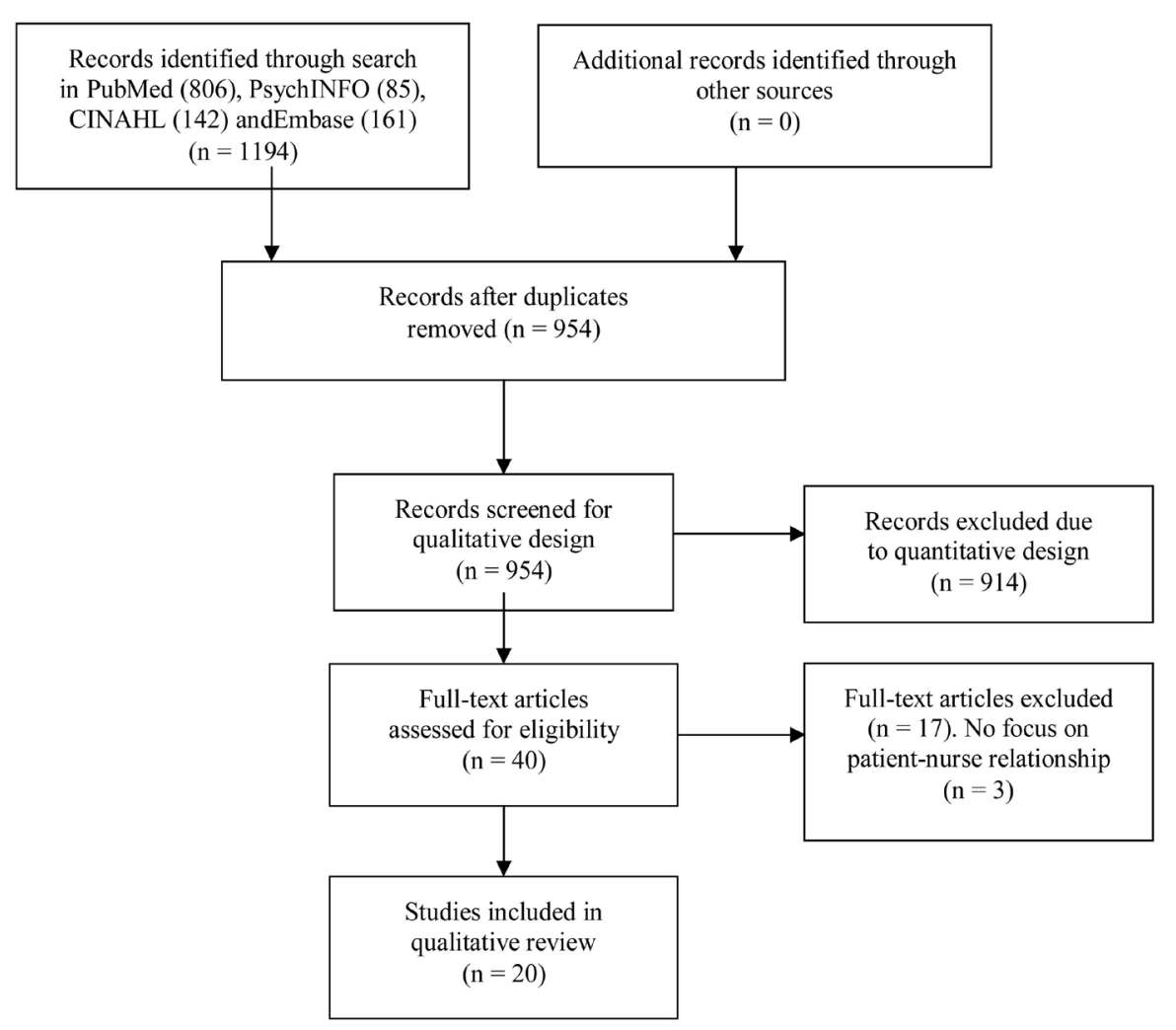

Figure 1. Literature identification process.

\subsubsection{Study Selection}

According to the inclusion criteria qualitative studies focusing on patients' experiences of trust in the encounter with nurses, describing nursing that influences patients' experiences of trust and which was published in peer reviewed English language journals were selected. The abstracts of the studies were read, after which duplicates, reports, editorials, textbooks, unpublished dissertations, quantitative studies, studies on professionals other than nurses, peer experiences and in which patient experiences were not in focus were excluded. Thereafter the tree researchers read the titles and abstracts of the remaining research papers and selected20 papers to read in full.

\section{Results}

20 papers were included and assessed in this review (Table 1). The following categories were identified to answer the review question about patients' experiences of the meaning of trust in nursing (Table 2).

\subsection{Attitudes Related to Trust}

The results described trust-related issues as emotional and rational attitudes. Factors that fostered and facilitated trust were thoroughly described.

\subsubsection{Trust as Emotional, and Rational}

Core features of trust as a phenomenon were described as emotional and rational. As trust grew, persons with schizophrenia began to believe that the nurses were interested in and cared about them [25]. When patients with chronic kidney disease trusted the healthcare staff they felt no need to question decisions [26]. The importance of trust in the caring relationship in a home care setting was described [27]. This was demonstrated in a logical way in the context of palliative care; when the nurse responded to the patient in a trustworthy manner, a trusting relationship developed [28].

A study on service users admitted to a psychiatric hospital described trust as important for a positive experience and related to "safety" and "coercion" as it was described in situations where the patients felt that their 
Table 1. Overview of included articles.

\begin{tabular}{llll}
$\begin{array}{l}\text { No/ } \\
\text { year }\end{array} \quad$ Author/title & $\begin{array}{l}\text { Objective/aim/ } \\
\text { research questions }\end{array}$ & Methods & $\begin{array}{l}\text { Key results/conclusion related to } \\
\text { trust }\end{array}$ \\
\hline
\end{tabular}

Cain et al.

Patient

experiences of

transitioning

1) from hospital to

2012 home: An

ethnographic

quality

improvement

project.

Gunther et al.

Barriers and

enablers to

managing

obesity in

2)

general

2012 practice: $a$

practical

approach for use

in

implementation

activities.

Brown et al.

Actions speak

louder than

words: the

3) embodiment of

trust by

healthcare

professionals in

gynae-oncology.

Nygardh et al.

The experience

of empowerment

4) in the

2012 patient-staff

encounter: the

patient's

perspective.
To develop a richly detailed, patient-centered

view of patient and caregiver needs in the hospital-to-home transition.

To uncover and describe barriers and enablers to implementing NICE's recommendations on the management of obesity in adults in general practice, using practical qualitative methods.

Undefined.

To explore empowerment within the patient-staff encounter as experienced by out-patients with chronic kidney disease.
Ethnographic approach, participant observation, in-depth, semi-structured video recorded interviews. 24 adult inpatients hospitalized for a range of acute and chronic conditions and characterized by variety in diagnoses, illness severity, planned or unplanned hospitalization, age, and ability to self manage.

A qualitative study. Semi structured interviews with seven general practitioners, seven practice nurses and nine overweight or obese patients, exploring their views and experiences on the implementation of NICE guidelines on obesity. The interviews were undertaken and analysed by a health professional with support of a health service researcher; they were recorded and transcribed verbatim and analysed using a thematic framework approach.

This article draws on qualitative data from semi-structured interviews with cervical cancer patients.

Qualitative interview study. 20 patients with chronic kidney disease. The interviews were subjected to latent content analysis.
During the hospital-to-home transition, patients and caregivers expressed six experiences in which one of them was "feeling connected to and trusting providers". This is one type of support which will help broaden understanding and reduce readmission.

Barriers and enablers of implementing NICE guideance on obesity was examined. Trust between practitioners and patients were perceived as one of several enablers to such implementation.

The significance of body work in winning or, on occasions, undermining trust emerged as a key theme. Trust bridges the present with the future and thus makes apparent how seemingly "detached" forms of body work are connected to the emotion-work of the caring role and the craftwork of body work as touch.

Five of the seven sub-themes emerging from the analysis represented empowerment: Accessibility according to need, Confirming encounter, Trust in the competence of the healthcare staff, Participation in decision-making, Learning enables better self-management. The other two represented non-empowerment: Meeting with nonchalance, Lack of dialogue and influence. From the seven sub-themes, one comprehensive theme was generated: Creation of trust and learning through encounter.

Alsen et al. Patients' illness

25 patients were interviewed four months after a myocardial infarction. In accordance with grounded theory methodology, perception of myocardi months after $a$ myocardial infarction four months after a myocardial infarction. data collection and analysis were carried out simultaneously.
Two core categories: "trust in oneself" vs. "trust in others"; belief in one's own efforts to control the illness; and “illness reasoning”, lines of thought about illness identity. 


\section{Continued}

Gilburt et al. The importance of relationships in mental health care: $a$

6) qualitative study 2008 of service users' experiences of psychiatric hospital admission in the UK.

Piippo \& Aaltonen

7) Mental health

2008 care: trust and mistrust in different caring contexts.

Wiersma \& Pedlar 8) The nature of 2008 relationships in alternative dementia care environments.

Hordern \& Street Issues of 9) intimacy and 2007 sexuality in the face of cancer: the patient perspective.

Sacks J.L., Nelson J.P. 10) A theory of 2007 nonphysical suffering and trust in hospice patients.

Mauleon A.L., Palo-Bengtsson 11) L., Ekman S.L. 2007 Patients experiencing local anesthesia and hip surgery.
To explore the experiences of admission to acute psychiatric hospital from the perspective of services users.

To identify the factors that make trust within the context of public mental health possible. We also consider the question of patients' trust in the whole caring system.

To examine the experiences of older adults with dementia while they were in long-term care and while they were in a summer-camp setting.

Draws on data from a larger study into issues of intimacy and sexuality from the perspectives of patients and health professionals in cancer and palliative care.

To uncover participants’ experiences of nonphysical suffering and what was helpful during this time.

To show that the experience of local anesthesia and a surgical situation meant to patients.
User-led study, a participatory approach. 19 service users who had all had inpatient stays in psychiatric hospitals in London were interviewed in the community.

Individual interviews with 22 psychiatric patients, who were also users of social services. A qualitative method based on the grounded theory approach. The main focus in the analysis was on how the patients had experienced the contexts of the caring systems and how trust was created or not within them.

Participant observation and interviews to gain an understanding of the experiences of seven residents of the long-term care facility.

\section{A 3-stage reflexive inquiry} involved semistructured participant interviews $(\mathrm{n}=82)$, textual analysis of national and international clinical practice guidelines $(\mathrm{n}=33)$, and participant feedback at 15 patient and health professional educational forums. This article presents the analysis of 50 patient interviews.

18 chronically ill patients. Grounded theory study.

An interpretive phenomenological method developed by Benner was used to extract the experience of what it means to be in local anesthesia and surgery. Seven patients experiencing local anesthesia and hip surgery.
Three codes, treatment, freedom and environment defined the role of hospital and its physical aspects. Themes of communication, safety, trust, coercion, and cultural competency contributed to the concept of relationships.

Categories creating trust were found. Acceptance of the patient's expertise concerning his/her life situation, openness and joint discussions concerning knowledge are important. Trust is closely connected to autonomy and power: patients feel that trust increases as their experience of autonomy increases and in such situations power is not owned by any one person.

Differing strategies were employed by residents. In a supportive relationship, participants used humor and reminisce. At the summer camp, relationships were dramatically altered and included elements of equality; personal interactions; and attention, reciprocity, and trust.

Five clusters of responses to a cancer diagnosis: "focus on survival," "trust in health professional," "desire for choices,” "search for normality,” and "need for negotiated communication."

Trust was uncovered as a central issue within nonphysical suffering, whereas meaning was the vehicle that enabled the individual to move within the suffering. Trust included the categories of dynamic experience, losing trust, and dealing to regain trust. Participants identified nurse trustworthiness as important for decreasing energy expenditures associated with suffering.

The well-being and comfort of patients is compromised by challenges such as severe pain and long waits, which may be experienced as endless and which leave the patient thinking of nothing else. By contrast, the experience of trust helps the patient to feel control even in situations where the treatment is hard to grasp. Local anesthesia and surgery force patients to overcome and handle experiences of pain, trust and distrust, feelings of alienation and unreality. 


\section{Continued}

\begin{tabular}{|c|c|c|}
\hline $\begin{array}{l}\text { 12) } \\
2007\end{array}$ & $\begin{array}{l}\text { Ekman I., } \\
\text { Ekstrand L., } \\
\text { Schaufelberger } \\
\text { M. } \\
\text { Pulmonary } \\
\text { oedema—a life } \\
\text { threatening } \\
\text { disease. }\end{array}$ & $\begin{array}{l}\text { To describe the health } \\
\text { history of patients after } \\
\text { pulmonary oedema and } \\
\text { investigate how they } \\
\text { perceive their condition } \\
\text { and treatment. }\end{array}$ \\
\hline $\begin{array}{l}\text { 13) } \\
2006\end{array}$ & $\begin{array}{l}\text { Donnelly \& } \\
\text { Wiechula } \\
\text { The lived } \\
\text { experience of a } \\
\text { tracheostomy } \\
\text { tube change: a } \\
\text { phenomenologic } \\
\text { al study. }\end{array}$ & $\begin{array}{l}\text { To investigate the lived } \\
\text { experience patients have } \\
\text { of a tracheostomy tube } \\
\text { change. }\end{array}$ \\
\hline $\begin{array}{l}\text { 14) } \\
2006\end{array}$ & $\begin{array}{l}\text { Brown et al. } \\
\text { Waiting for a } \\
\text { liver transplant. }\end{array}$ & $\begin{array}{l}\text { To understand better what } \\
\text { it means for a transplant } \\
\text { patient to wait, the authors } \\
\text { explore in this } \\
\text { phenomenological study } \\
\text { the meaning that people } \\
\text { with liver failure ascribe to } \\
\text { the experience of waiting } \\
\text { for a transplant. }\end{array}$ \\
\hline
\end{tabular}

Lindgren $\mathrm{H}$.,

Hildingsson I., Rådestad I.

15) A. Swedish

2006 interview study: parents'

assessment of

risks in home

births.

Leiphart L.R., Barnes M.G.

The client

16)

experience of

assertive

community

treatment: a

qualitative

study.

Langley G.C., Klopper $\mathrm{H}$.

Trust as a

foundation for

17) the therapeutic

2005 intervention for

patients with

borderline

personality

disorder. for a transplant.

To describe home-birth risk assessment by parents.

Clients with schizophrenia's reactions to the intensive form of treatment delivery (Assertive Community Treatment (ACT)) were explored.

To develop a practice-level model for the facilitation of mental health of patients diagnosed as having Borderline Personality Disorder by the community psychiatric nurse.
Interviews were performed focusing on the patients' conceptions of the illness, current situation and effects of pulmonary oedema on daily life.

A phenomenological approach. Participants were interviewed with their responses being transcribed into a text. This text has been subject to hermeneutic analysis using the theories of Paul Ricoeur. This hermeneutic approach has required using the text (discourse) as the focus of the interpretation.

Nine interviews using

phenomenological methods of inquiry as a guide for analysis. Data were analysed using a phenomenological approach.

Utilizing depth interviews and Grounded Theory descriptive and contextual study using an "interpretive descriptive approach".
Semi-structured interview guide.

Analysis of the interviews revealed five categories: A suffocating feeling; trust in care providers; medication; dealing with existential issues alone or with relatives; concurrent diseases affecting daily life. Experiencing Pulmonary oedema is anxiety-provoking and patients should be regularly and carefully monitored.

The experience of a tracheostomy tube change is more complex than that of simply a physical sensation. There is a need for participants to prepare themselves psychologically, a process that requires not only the trust of nursing staff but also the assessment by the participant that the nursing staff member has a level of competence to perform the task.

Eight core themes emerged from the data. The experience of waiting includes transformations, doctors, teams and trust, elation to despair, loss, questioning the process, searching, coping, and the paradox of time. Trust and faith in the transplant team were judged to be a positive element for "surviving" on the waiting list.

The parents had a fundamental trust that the birth would take place without complications, and they experienced meaningfulness in the event itself. A fundamental trust in the woman's independent ability to give birth was central to the decision to choose a home birth.

As providers assisted clients with practical needs, clients began to develop trust, which fostered a sense of belonging and relationship, leading toward a positive motivation regarding treatment.

A qualitative, exploratory,
Patients' subthemes: Trust a foundation, Holding and caring, Available and accessible, Listening - trying to understand, Professional, Hope. 


\section{Continued}

\begin{tabular}{|c|c|c|c|c|}
\hline $\begin{array}{l}18) \\
2004\end{array}$ & $\begin{array}{l}\text { Thomas et al. } \\
\text { The Caring } \\
\text { Relationships } \\
\text { Created by } \\
\text { Nurse } \\
\text { Practitioners } \\
\text { and the } \\
\text { Ones Nursed: } \\
\text { Implications for } \\
\text { Practice. }\end{array}$ & $\begin{array}{l}\text { To uncover the caring } \\
\text { experienced in the } \\
\text { NP-nursed } \\
\text { relationship. }\end{array}$ & $\begin{array}{l}\text { Phenomenological study. The } \\
\text { design was Schoenhofer's Nursing } \\
\text { as Caring research praxis } \\
\text { approach. } 14 \text { key informants were } \\
\text { interviewed in their respective } \\
\text { outpatient settings. }\end{array}$ & $\begin{array}{l}\text { Attributes of the caring between the } \\
\text { NPs and the ones nursed composed the } \\
\text { main outcome measures. } \\
\text { The themes emerging from the } \\
\text { dialogue data were love, respect, trust, } \\
\text { mutuality, spiritual expression, and } \\
\text { enhanced personhood. }\end{array}$ \\
\hline $\begin{array}{l}\text { 19) } \\
2004\end{array}$ & $\begin{array}{l}\text { Mok E., Chiu } \\
\text { P.C. } \\
\text { Nurse-patient } \\
\text { relationships in } \\
\text { palliative care. }\end{array}$ & $\begin{array}{l}\text { To report a study } \\
\text { exploring aspects of } \\
\text { nurse-patient relationships } \\
\text { in palliative care. }\end{array}$ & $\begin{array}{l}\text { Qualitative data from } 10 \text { hospice } \\
\text { nurses and } 10 \text { terminally ill } \\
\text { patients by means of open ended } \\
\text { unstructured interviews. }\end{array}$ & $\begin{array}{l}\text { Four major categories emerged from } \\
\text { the perspectives of patients and nurses: } \\
\text { 1) forming a relationship of trust; 2) } \\
\text { being part of the family; 3) refilling } \\
\text { with fuel along the journey of living } \\
\text { and dying; and 4) enriched } \\
\text { experiences. }\end{array}$ \\
\hline $\begin{array}{l}20) \\
2003\end{array}$ & $\begin{array}{l}\text { Battaglia et al. } \\
\text { Survivors of } \\
\text { Intimate Partner } \\
\text { Violence Speak } \\
\text { Out. }\end{array}$ & $\begin{array}{l}\text { To identify characteristics } \\
\text { that facilitate trust in the } \\
\text { patient-provider } \\
\text { relationship among } \\
\text { survivors of intimate } \\
\text { partner violence (IPV). }\end{array}$ & $\begin{array}{l}27 \text { female survivors of IPV. Semi } \\
\text { structured, open-ended interviews. } \\
\text { Grounded theory methods. A } \\
\text { community advisory group, } \\
\text { composed of advocates, counselors } \\
\text { and IPV survivors, helped interpret } \\
\text { themes. }\end{array}$ & $\begin{array}{l}\text { These IPV survivors identified } 5 \\
\text { dimensions of provider behavior that } \\
\text { facilitate trust in their clinical } \\
\text { relationship. Strengthening these } \\
\text { provider behaviors may increase trust } \\
\text { with patients and thus improve } \\
\text { disclosure of and referral for IPV. }\end{array}$ \\
\hline
\end{tabular}

Table 2. Overview of the results.

\begin{tabular}{|c|c|c|c|c|}
\hline Categories & Attitudes related to trust & Experiences of trust & The patient-nurse relationship & Where trust occurs \\
\hline \multirow{2}{*}{ Sub-categories } & $\begin{array}{c}\text { Trust as emotional } \\
\text { and rational }\end{array}$ & $\begin{array}{l}\text { Experiences of trust } \\
\text { through predictability and } \\
\text { empowerment }\end{array}$ & $\begin{array}{l}\text { The trustor's qualities, } \\
\text { skills, and behavior }\end{array}$ & $\begin{array}{l}\text { Trust related to situations, } \\
\text { role and competence }\end{array}$ \\
\hline & $\begin{array}{l}\text { Facilitating and } \\
\text { fostering trust }\end{array}$ & $\begin{array}{l}\text { Experiences of trust } \\
\text { through feeling safe, } \\
\text { accepted and cared for }\end{array}$ & $\begin{array}{l}\text { Communication between } \\
\text { the trustor and the trustee }\end{array}$ & $\begin{array}{c}\text { Trust related to } \\
\text { organizational level }\end{array}$ \\
\hline
\end{tabular}

safety were at risk [29]. Trust was described as a key enabler in helping obese patients to lose weight [30].

Trust in oneself was associated with belief in one's own ability to influence and control illness, which could be related to prevention (heart attack) [31]. However, trust in others may be associated with being less active and motivated to improve one's health situation. Less interest or confidence in one's own ability to control the illness was described. In this situation the patients trusted the actions and care of powerful others, such as healthcare professionals and relatives, rather than their own efforts [31].

\subsubsection{Facilitating and Fostering Trust}

In the context of survivors of intimate partner violence, various facilitators for trust were described: nurses' openness and willingness to talk; professional competency; practice style, interest, concern, confidentiality, shared control; caring, nonverbal, non-judgmental empowerment and persistence in addition to emotional equality as well as willingness and ability to engage on a personal level [32]. In persons with schizophrenia, meeting pragmatic needs and listening to the patient fostered trust [25]. The creation of a dialogical process between nurses and patients with psychiatric illness created trust [33]. Views of patients with borderline personality disorders on certain essential conditions for developing trust were described: being available, understanding, caring and a feeling of being emotionally as well as physically safe [34]. A trusting relationship was outlined in four themes: 1) understanding the patient's needs; 2) exhibiting caring actions and attitudes; 3) providing holistic care; and 4) acting as the patient's advocate [28].

\subsection{Experiences of Trust}

This category described factors related to when and how trust can be sensed as well as factors enabling trust. 


\subsubsection{Experiences of Trust through Predictability and Empowerment}

A study on home birth risk assessment found that parents who had been well prepared by a familiar midwife felt that they could cope with the forthcoming birth [35]. In contrast, stress and anxiety were reported among elderly people after hip surgery under local anaesthesia when they had no sense of trust and their lack of knowledge about surgery made it difficult to keep track of and participate in their own situation [36]. Trust made the participants with schizophrenia value early detection of symptoms and provided a feeling of managing life better, which meant that they were more open to encouragement and advice to push themselves more towards improvement [25].

A link was described between trust and empowerment and that trust helped to prevent embarrassment and shame in survivors of partner violence [32]. Trust in the care providers assisted patients who had undergone local anaesthesia and hip surgery to feel in control even when the treatment was difficult to understand [36]. Hope emerged as trust developed and patients began to trust themselves and others [34].

\subsubsection{Experiences of Trust through Feeling Safe, Accepted and Cared for}

Feeling safe was related to basic needs such as having someone to rely on; the provision of shelter and a homelike setting, being sure that one's needs will be met and feeling cared for. Experiences of trust was associated with feeling safer, more confident, being heard and less angry; the participants felt accepted, cared about and a sense of belonging [25]. The risk of complications in home births was counterbalanced by confidence in the midwife [35]. Experiences of trust were also related to being respected, feeling accepted as a person, not objectified [34] and confidentiality [32]. Trust in a transplant team was judged to be "a positive element for 'surviving' on the waiting list” (p. 126) when waiting for a liver transplant [37].

In patients with myocardial infarction, trust in powerful others led to less interest in their own ability to control the illness [31]. For older adults in long term care, trust meant opening up to the nurses on a summer holiday for people suffering from dementia about issues they might otherwise not have revealed to others [38]. Trust was central for patients suffering from chronic mental illness [39]. Trust can be shattered by suffering and linked to believing in one's own constructed reality, which enabled hope and provided meaning. Three categories of trust were developed in this context: the dynamic experience of trust, losing trust and dealingto regain trust [39].

\subsection{The Patient-Nurse Relationship}

Trust was fundamental for caring in the patient-nurse relationship [27], essential for the establishment and maintenance of a therapeutic alliance [34]. In the context of the transition from hospital to home, one participant expressed that she needed to trust someone familiar with her own experiences and that she tried to stick to one person (p. 97) [40]. In a study on patients with dementia, two types of relationships were categorised: functional and supportive; "functional relationships focus on tasks, while supportive relationships are characterized by a sense of trust” (p. 103) [38]. In the present review, this category had two sub-categories:

\subsubsection{The Trustor's Qualities, Skills and Behavior}

The trustors' skills and behaviorthat enabled the development of trust in the relationship with survivors of intimate partner violence were outlined in five dimensions: 1) nurses being willing to discuss the abuse; 2) nurses demonstrating competence by asking the right questions and being familiar with medical and social histories; 3 ) nurses being practical, accessible, confident, and promoting shared decision making; 4) nurses being caring, non-judgmental and compassionate, providing empowerment as well as being persistent and committed; and 5) nurses sharing personal feelings and friendliness [32]. In patients with dementia, trust had to be present between the patients and nurses "for flirting, openness, sharing personal stories and physical affection"(p. 106) [38]. The trustor's qualities, skills and behaviour with gestures and body language indicating caring, attention, warmth and patience [32]. Trust was associated with nurses taking time, sitting down and answering questions, exhibiting interest and showing concern as well as sharing experiences and emotions [32]. Trust was created by nurses who demonstrated caring by positive attention [25], caring actions and attitudes [28]. In patients with chronic kidney disease, the sense of security was nurtured when the staffs were available and the feeling of trust was nurtured through the dialogue between the staff and the patient [26]. Providing holistic care and exhibiting genuine interest as well as specific care in accordance with individual needs were described. Understanding the patient's needs and suffering created trust [28]. Other important issues concerned the qualities of the trustor such as per- 
sistence and not giving up [32]; initiating and taking part in the intellectual and emotional process [35]; relying on the team's insight and proactive treatment [25]; keeping in contact not only when difficulties arise [25]; being non-judgmental, confirming the patients' experiences, not shaming or blaming but encouraging, remaining hopeful, being aware of the options, being willing and able to engage on a personal level and sharing their own life experiences and emotions [32]; as well as being honest, flexible calm, empathetic [34] and emotionally accessible [35].

The patients with pulmonary oedema reported high trust in the care providers, particularly in their medical expertise [41]. Confidence in midwives was highlighted as it counterbalanced the risk of possible complications [35]. One study described that when a nurse responded to a patient in a trustworthy way, a relationship characterized by trust and connection developed [28].

\subsubsection{Communication between the Trustor and Trustee}

Trust was described as being in tune with the other [35]. This may be associated with communication such as nurses informing about risk, maintaining confidentiality, interacting with and relating to patients as adults, acting as advisor or patient advocate, being engaged and providing assistance. Prior friendship with the midwife was described as a great emotional benefit, while trust was related to being a good friend, a part of the family [28] or being familiar [32]. Being heard and understood in such a relationship was important for trust, as were openness and willingness to talk and listen [32]. The need to engage in conversation was highlighted, for instance trying to clarify the content, adopting a listening attitude and demonstrating that one is trying to understand [34].

\subsection{Where Trust Occurs}

In the context of psychiatric patient in the outpatient setting, one study claimed that trust can be created in the traditional caring context when patients feel that they are participating in their care process, which is dependent on the nurse's behavior. Here, trust refers to an individual professional as opposed to the care system. Patients reported increased autonomy and the emergence of trust in such two-way relationships [33]. The following two sub-categories were described:

\subsubsection{Trust Related to Situations, Roles and Competence}

In the context of gynae-oncology, one study claimed that trust is likely to vary across different clinical settings as they relate trust to "a particular physiological, emotional, clinical, cultural and gendered context of body work" (p. 292) and reported that gender may influence the embodied phenomenon of trust in patients with cervical cancer [42]. For those with schizophrenia, the act of bringing service to the patient in a caring manner may result in fostering trust. Patients with schizophrenia who trusted in the nurses believed that the team cared about them [25].

Several papers illuminated the link between trust and competence. Trust was nurtured by the patient-nurse dialogue, that the participants trusted in staff members' competence and a majority felt they were receiving the best care possible [26]. Trust was linked to competent nurses who managed situations [29]. Trust was related to reliance on the team's insight and proactive treatment [25]. Other issues related to competence were discussions about medical issues and abuse, being knowledgeable and thorough as well as a long-term caring relationship that made the provider familiar with and interested in each individual [32]. One study associated trust with professional factors such as maintaining confidentiality and interacting with patients as adults[34], while others referred to the need to respond in a trustworthy way [28]. In the context of tracheostomy tube change, patients needed to prepare themselves psychologically, which required trust that the nurses had the necessary competence to perform such a complex task [43]. Nurses who were experienced as professional, flexible, empathetic, confidential, related to the patient as an adult and remained calm were deemed trustworthy whereby a foundation for the therapeutic contract could be laid [34].

\subsubsection{Trust Related to the Organizational Level}

Organizational issues were mentioned such as staff being instant accessible [25]; availability and easy to contact [32]. A set time to contact the therapist and negotiation of a formal agreement between patient and therapist were described [34]. Time was an issue because it is required to develop the relationship [34] and to sit down 
and listen [32]. A study of factors that enable trust in the context of public mental healthcare highlighted the importance of creating trust through dialogue and not through the system, stating that the participants in their study never mentioned trust in the latter [33].

\section{Discussion}

The aim of this study was to report a synthesis of the literature on the meaning of trust in the context of patients' experiences of nursing, and the review question was: How do patients describe the meaning of trust in nursing? This review illuminates the meaning of trust described from the patients' personal experiences which vary across the clinical setting as demonstrated in the different studies. The review report the patients' view of the meaning of trust, as it is described and related to a variety of attitudes, experiences, relationship and context.

Attitudes related to trust are based on the patients' view of an emotional and rational experience. The gap in the understanding of the depth [12] and meaning of trust [18] can be reduced by an exploration of clinical studies illuminating patients' own descriptions. These experiences comprise both a feeling and an awareness of trust as described in this review. Such core features are reasonable and lead to the feeling of being taken care of, dispensing with the need to ask questions, relying on the other, feeling safe and better able to manage the illness, thus these features constitute a key enabler in overcoming problems. However, one should be aware of the finding that the patient may be less motivated to engage in his/her own situation and make decisions as a consequence of complete trust in the nurse.

Facilitating and fostering trust are related to communication, nurses being open, competent, practical, interested, concerned, confident and sharing control, which is in line with literature which describes trust as a process and outcome [10]. The review demonstrates that nurses who facilitate trust are engaged, listen and create a dialogical process, are available and act in a safe, holistic manner as the patient's advocate. These actions are opportunities to create faith, hope and meaning as described in previous literature [14].

Experiences of trust are essential for caring; the trustee believes that the trustor will safeguard his/her interest. Predictability and empowerment are created when patients are informed, prepared or know in advance, leading to early detection of symptoms, better ability to manage life, trust in oneself, hope and being more open to pushing oneself. Patient empowerment prevents embarrassment and shame by providing a sense of control over the treatment, while a lack of trust gives rise to anxiety, stress as well as difficulty understanding, keeping track of and participating in one's own situation.

Trust has been characterized as reliance on and confidence in others and its basic attributes as time, reliance, risk and fragility [8]. Feeling safe, accepted and cared for is fundamental for the establishment and maintenance of the therapeutic relationship and led to the patient being open about issues he/she might not reveal to others. Feeling safe, being provided with shelter and a home-like environment are associated with a sense of confidence and respect.

The patient-nurse relationship is intimate and personal for the latter. For nurses to be experienced as trustworthy, they must exhibit the following qualities: communication skills, competence, practical skills and behave in a caring and non-judgmental way, as well as being friendly, warm and patient.

The review reveals the importance of communication between the trustor and trustee for the creation of trust. Issues such as information, confidentiality, advice, being the patient's advocate or being familiar with the nurses are crucial for a trusting relationship. Being heard and understood is essential for the patient. Previous findings highlight trust as the basis of the relationship between healthcare professionals and patients [1]-[3]. Gestures and body language associated with care, attention, warmth and patience indicate a trustworthy character. The patient opens up when she/he expects the nurse to act in a trustworthy manner. This is in line with previous literature which illuminates factors related to the potential for shame, humiliation and power imbalance and demonstrates that the best caring actions take place in a setting where the patient receives understanding, treatment and the nurse remains by the patient's side [1].

The contextual aspects of trust are illuminated in the category Where trust occurs. In a traditional caring context, the development of trust is dependent on the nurse's behavior. Trust is related to situations, roles and competence. In certain contexts, patients sense that nurses care about them and trust can be nurtured. Trust occurs in a setting where nurses exhibit competence and knowledge, share information and maintain confidentiality. Trust related to the organizational level demonstrate some external issues of importance for trust on the part of the patient; easy access, time, level of knowledge and caring. This is in accordance with literaturewhich highlight the 
importance of management including recruitment, training and developing moral understanding and motivation in the health workers, when generating trust in the healthcare system [13]. Trust should not only be developed by the individual nurse at an interpersonal level, as economic and social structures are also important [9].

\section{Methodological Considerations}

The present review only includes a synthesis of qualitative studies only. Literature argues that both quantitative and qualitative methods are necessary in order to make policymakers understand healthcare barriers. A mixed-method design and an interdisciplinary research paradigm would highlight other aspects of patients' experiences of trust, thus differing in terms of epistemological and ontological foundations [20].

The analysis of the present review was deemed interpretative, although the interpretation was not on a high level, as the categories were intended to reflect the different focuses of trust experienced by patients. Literature highlights the importance of clarifying the aim and procedure of the review as well as whether the thematic analysis is descriptive or interpretative [20].

Issues related to the limitations of the included papers as well as the methodological considerations of the present review study may be discussed according to the checklist of the methodological quality of published literature [24]. The review has some weaknesses, such as failure to discuss saturation or some of the weak aspects in the included papers; the relationship between the researcher and participants, the researchers' own role and potential bias during data collection or information about how ethical standards were maintained [24]. Data analyses should be sufficiently rigorous, meaning that they describe the analysis process and the development of the themes or categories. This aspect was deemed weak in some of the papers that failed to critically examine the researchers' own role, potential bias and influence (Appendix 1 and Appendix 2). According to the CASP [24], critical criteria are that the recruitment strategy is appropriate for the aims of the review and that the authors provide a detailed description of the selection of participants. Information about how and where the interviews were performed, whether or not they were audio-taped, the interview guide and any modifications to it should be provided as well as a discussion of the credibility of the research questions. An overview and the results of quality assessment of the included studies may be found in Appendix 1 and an example of assessment may be found in Appendix 2.

\section{Conclusion}

A typical nursing approach can be difficult to identify as nurses and nursing seems to be concealed in collective terms such as care givers, healthcare professionals, staff, personnel, practitioners, providers etc. It is important to highlight and develop nursing approaches. Failure to do so will marginalize the influence of nursing and nursing research in healthcare. Patients' experiences of trust in nursing are dependent on nurses' knowledge and engagement in the dialogue as well as on ad hoc meetings in a safe context.Nursing practice and trust should be investigated due to the intimate patient-nurse relationship.

\section{Implications for Nursing Practice}

An informed debate should be stimulated among clinical nurse researchers and nursing graduates in contexts such as nursing supervision and focus groups. Reflection on a trusting relationship with the patient is necessary for a deeper conceptual understanding of trust in nursing.Nurse educators and leaders should ensure that nurses develop attitudes and knowledge as a foundation for establishing a trusting patient-nurse relationship.

Clinical nurse researchers, nurse supervisors, managers and nurse educators should discuss different areas of trust during nursing supervision and focus-group meetings as well as with nursing graduates to ensure that nurses develop knowledge of how to create a trusting patient-nurse relationship.

Clinical studies should highlight and present evidence of trust as fundamental for all nursing interventions. Patient descriptions of the meaning of trust should be of interest to clinical nurse researchers due to the fact that such descriptions are individual and influenced by each patient's own history and context.

\section{References}

[1] Seetharamu, N., Iqbal, U. and Weiner, J.S. (2007) Determinants of Trust in the Patient-Oncologist Relationship. Palliative \& Supportive Care, 5, 405-409. http://dx.doi.org/10.1017/S1478951507000600 
[2] de Raeve, L. (2002) The Modification of Emotional Responses: A Problem for Trust in Nurse-Patient Relationships? Nursing Ethics, 9, 465-471. http://dx.doi.org/10.1191/0969733002ne536oa

[3] Belcher, M. and Jones, L.K. (2009) Graduate Nurses Experiences of Developing Trust in the Nurse-Patient Relationship. Contemporary Nurse, 31, 142-152. http://dx.doi.org/10.5172/conu.673.31.2.142

[4] Dinc, L. and Gastmans, C. (2012) Trust and Trustworthiness in Nursing: An Argument-Based Literature Review. Nursing Inquiry, 19, 223-237. http://dx.doi.org/10.1111/j.1440-1800.2011.00582.x

[5] Pask, E.J. (1999) Trust: An Essential Component of Nursing Practice-Implications for Nurse Education. Nurse Education Today, 15, 190-195. http://dx.doi.org/10.1016/S0260-6917(95)80105-7

[6] Martinsen, K. (2005) Samtalen, skjønnet og evidensen (no.). Akribe, Gjøvik, 166.

[7] Delmar, C. (2012) Utvecling av en omvårdnadsteori om livsfenomen-med Kari Martinsens omsorgsfilosofi som förståelseshorisont. In: Jörgensen, B.B. and Steenfeldt, V.Ö., Eds., Omvårdsteori Som Referensram, Kina, Forfattarna och Liber AB, 86-101.

[8] Dinc, L. and Gastmans, C. (2013) Trust in Nurse-Patient Relationships: A Literature Review. Nursing Ethics, 20, 501516. http://dx.doi.org/10.1177/0969733012468463

[9] Connell, N.A. and Mannion, R. (2006) Conceptualisations of Trust in the Organisational Literature: Some Indicators from a Complementary Perspective. Journal of Health Organization and Management, 20, 417-433. http://dx.doi.org/10.1108/14777260610701795

[10] Johns, J.L. (1996) A Concept Analysis of Trust. Journal of Advanced Nursing, 24, 76-83. http://dx.doi.org/10.1046/j.1365-2648.1996.16310.x

[11] McHale, D. and Deatrick, J. (2000) Trust between Family and Health Care Provider. Journal of Family Nursing, 6, 210-230.

[12] Hupcey, J.E., Penrod, J., Morse, J.M. and Mitcham, C. (2001) An Exploration and Advancement of the Concept of Trust. Journal of Advanced Nursing, 36, 282-293. http://dx.doi.org/10.1046/j.1365-2648.2001.01970.x

[13] Gilson, L. (2006) Trust in Health Care: Theoretical Perspectives and Research Needs. Journal of Health Organization and Management, 2, 359-375. http://dx.doi.org/10.1108/14777260610701768

[14] Lindstrom, U. (2001) Psykiatrisk sykepleie: Teori, verdier og praksis / Unni Å. Lindström; Oversatt av Inger Aanderaa. Gyldendal Akademisk, Oslo.

[15] Laugharne, R. and Priebe, S. (2006) Trust, Choice and Power in Mental Health: A Literature Review. Social Psychiatry and Psychiatric Epidemiology, 41, 843-852. http://dx.doi.org/10.1007/s00127-006-0123-6

[16] Epstein, R.M. (2006) Making Communication Research Matter: What Do Patients Notice, What Do Patients Want, and What Do Patients Need? Patient Education and Counseling, 60, 272-278. http://dx.doi.org/10.1016/j.pec.2005.11.003

[17] Bell, L. and Duffy, A. (2009) A Concept Analysis of Nurse-Patient Trust. British Journal of Nursing, 18, 46-51. http://dx.doi.org/10.12968/bjon.2009.18.1.32091

[18] Hupcey, J.E. and Miller, J. (2006) Community Dwelling Adults’ Perception of Interpersonal Trust vs. Trust in Health Care Providers. Journal of Clinical Nursing, 15, 1132-1139. http://dx.doi.org/10.1111/j.1365-2702.2006.01386.x

[19] Hansen, B.S., Rørtveit, K., Leiknes, I., Morken, I., Testad, I., Joa, I., et al. (2012) Patient Experiences of UncertaintyA Synthesis to Guide Nursing Practice and Research. Journal of Nursing Management, 20, 266-277. http://dx.doi.org/10.1111/j.1365-2834.2011.01369.x

[20] Dixon-Woods, M., Agarwal, S., Jones, D., Young, B. and Sutton, A. (2005) Synthesising Qualitative and Quantitative Evidence: A Review of Possible Methods. Journal of Health Services Research \& Policy, 10, 45-53.

[21] Noyes, J. and Popay, J. (2007) Directly Observed Therapy and Tuberculosis: How Can a Systematic Review of Qualitative Research Contribute to Improving Services? A Qualitative Meta-Synthesis. Journal of Advanced Nursing, 57, 227-243. http://dx.doi.org/10.1111/j.1365-2648.2006.04092.x

[22] Ring, N., Jepson, R., Hoskins, G., Wilson, C., Pinnock, H., Sheikh, A., et al. (2011) Understanding What Helps or Hinders Asthma Action Plan Use: A Systematic Review and Synthesis of the Qualitative Literature. Patient Education and Counseling, 85, e131-e143. http://dx.doi.org/10.1016/j.pec.2011.01.025

[23] Graneheim, U.H. and Lundman, B. (2004) Qualitative Content Analysis in Nursing Research: Concepts, Procedures and Measures to Achieve Trustworthiness. Nurse Education Today, 24, 105-112. http://dx.doi.org/10.1016/j.nedt.2003.10.001

[24] CASP, Critical Appraisal Skills Programme (2013) 10 Questions to Help You Make Sense of Qualitative Research. Critical Appraisal Skills Programme (CASP), Oxford. http://media.wix.com/ugd/dded87_29c5b002d99342f788c6ac670e49f274.pdf

[25] Leiphart, L.R. and Barnes, M.G. (2005) The Client Experience of Assertive Community Treatment: A Qualitative 
Study. Psychiatric Rehabilitation Journal, 28, 395-397. http://dx.doi.org/10.2975/28.2005.395.397

[26] Nygardh, A., Malm, D., Wikby, K. and Ahlström, G. (2012) The Experience of Empowerment in the Patient-Staff Encounter: The Patient's Perspective. Journal of Clinical Nursing, 21, 897-904. http://dx.doi.org/10.1111/j.1365-2702.2011.03901.x

[27] Thomas, J.D., Finch, L.P., Schoenhofer, S.O. and Green, A. (2004) The Caring Relationships Created by Nurse Practitioners and the Ones Nursed: Implications for Practice. Topics in Advanced Practice Nursing eJournal, 4.

[28] Mok, E. and Chiu, P.C. (2004) Nurse-Patient Relationships in Palliative Care. Journal of Advanced Nursing, 48, 475483. http://dx.doi.org/10.1111/j.1365-2648.2004.03230.x

[29] Gilburt, H., Rose, D. and Slade, M. (2008) The Importance of Relationships in Mental Health Care: A Qualitative Study of Service Users' Experiences of Psychiatric Hospital Admission in the UK. BMC Health Services Research, 8, 1-12. http://dx.doi.org/10.1186/1472-6963-8-92

[30] Gunther, S., Guo, F., Sinfield, P., Rogers, S. and Baker, R. (2012) Barriers and Enablers to Managing Obesity in General Practice: A Practical Approach for Use in Implementation Activities. Quality in Primary Care, 20, 93-103.

[31] Alsen, P., Brink, E. and Persson, L.O. (2008) Patients’ Illness Perception Four Months after a Myocardial Infarction. Journal of Clinical Nursing, 17, 25-33. http://dx.doi.org/10.1111/j.1365-2702.2007.02136.x

[32] Battaglia, T.A., Finley, E. and Liebschutz, J.M. (2003) Survivors of Intimate Partner Violence Speak Out: Trust in the Patient-Provider Relationship. Journal of General Internal Medicine, 18, 617-623. http://dx.doi.org/10.1046/j.1525-1497.2003.21013.x

[33] Piippo, J. and Aaltonen, J. (2008) Mental Health Care: Trust and Mistrust in Different Caring Contexts. Journal of Clinical Nursing, 17, 2867-2874. http://dx.doi.org/10.1111/j.1365-2702.2007.02270.x

[34] Langley, G.C. and Klopper, H. (2005) Trust as a Foundation for the Therapeutic Intervention for Patients with Borderline Personality Disorder. Journal of Psychiatric and Mental Health Nursing, 12, 23-32. http://dx.doi.org/10.1111/j.1365-2850.2004.00774.x

[35] Lindgren, H., Hildingsson, I. and Radestad, I. (2006) A Swedish Interview Study: Parents' Assessment of Risks in Home Births. Midwifery, 22, 15-22. http://dx.doi.org/10.1016/j.midw.2005.04.002

[36] Mauleon, A.L., Palo-Bengtsson, L. and Ekman, S.L. (2007) Patients Experiencing Local Anaesthesia and Hip Surgery. Journal of Clinical Nursing, 16, 892-829. http://dx.doi.org/10.1111/j.1365-2702.2007.01771.x

[37] Brown, J., Sorrell, J.H., McClaren, J. and Crewell, J.W. (2006) Waiting for a Liver Transplant. Qualitative Health Research, 16, 119-136. http://dx.doi.org/10.1177/1049732305284011

[38] Wiersma, E.C. and Pedlar, A. (2008) The Nature of Relationships in Alternative Dementia Care Environments. Canadian Journal on Aging, 27, 101-108. http://dx.doi.org/10.3138/cja.27.1.101

[39] Sacks, J.L. and Nelson, J.P. (2007) A Theory of Nonphysical Suffering and Trust in Hospice Patients. Qualitative Health Research, 17, 675-689. http://dx.doi.org/10.1177/1049732306298524

[40] Cain, C.H., Neuwirth, E., Bellows, J., Zuber, C. and Green, J. (2012) Patient Experiences of Transitioning from Hospital to Home: An Ethnographic Quality Improvement Project. Journal of Hospital Medicine, 7, 382-387. http://dx.doi.org/10.1002/jhm.1918

[41] Ekman, I., Ekstrand, L. and Schaufelberger, M. (2007) Pulmonary Oedema-A Life Threatening Disease. European Journal of Cardiovascular Nursing, 6, 259-264. http://dx.doi.org/10.1016/j.ejcnurse.2006.11.003

[42] Brown, P.R., Alaszewski, A., Swift, T. and Nordin, A. (2011) Actions Speak Louder Than Words: The Embodiment of Trust by Healthcare Professionals in Gynae-Oncology. Sociology of Health \& Illness, 33, 280-295. http://dx.doi.org/10.1111/j.1467-9566.2010.01284.x

[43] Donnelly, F. and Wiechula, R. (2006) The Lived Experience of a Tracheostomy Tube Change: A Phenomenological Study. Journal of Clinical Nursing, 15, 1115-1122. http://dx.doi.org/10.1111/j.1365-2702.2006.01384.x 
Appendix 1. Results of quality assessment of the included studies based on the The Critical Appraisal Skills Programchecklist for qualitative studies (CASP 2013). (Y: yes, N: no, U: unclear).

\begin{tabular}{lccccccccccccc}
\hline & Author & 1 & 2 & 3 & 4 & 5 & 6 & 7 & 8 & 9 & 10 & Assessment \\
\hline 1 & Cain 2012 & $\mathrm{Y}$ & $\mathrm{Y}$ & $\mathrm{Y}$ & $\mathrm{Y}$ & $\mathrm{Y}$ & $\mathrm{N}$ & $\mathrm{U}$ & $\mathrm{Y}$ & $\mathrm{Y}$ & $\mathrm{U}$ & Moderate \\
2 & Gunther et al. 2012 & $\mathrm{Y}$ & $\mathrm{Y}$ & $\mathrm{U}$ & $\mathrm{Y}$ & $\mathrm{Y}$ & $\mathrm{Y}$ & $\mathrm{N}$ & $\mathrm{U}$ & $\mathrm{U}$ & $\mathrm{U}$ & Low \\
3 & Brown et al. 2011 & $\mathrm{Y}$ & $\mathrm{Y}$ & $\mathrm{Y}$ & $\mathrm{Y}$ & $\mathrm{Y}$ & $\mathrm{N}$ & $\mathrm{Y}$ & $\mathrm{U}$ & $\mathrm{Y}$ & $\mathrm{Y}$ & Moderate \\
4 & Nygardh et al. 2011 & $\mathrm{Y}$ & $\mathrm{Y}$ & $\mathrm{Y}$ & $\mathrm{Y}$ & $\mathrm{Y}$ & $\mathrm{N}$ & $\mathrm{Y}$ & $\mathrm{Y}$ & $\mathrm{Y}$ & $\mathrm{Y}$ & High \\
5 & Alsen et al. 2008 & $\mathrm{Y}$ & $\mathrm{Y}$ & $\mathrm{Y}$ & $\mathrm{Y}$ & $\mathrm{Y}$ & $\mathrm{N}$ & $\mathrm{Y}$ & $\mathrm{Y}$ & $\mathrm{Y}$ & $\mathrm{Y}$ & High \\
6 & Gilburt et al. 2008 & $\mathrm{Y}$ & $\mathrm{Y}$ & $\mathrm{Y}$ & $\mathrm{Y}$ & $\mathrm{Y}$ & $\mathrm{Y}$ & $\mathrm{N}$ & $\mathrm{Y}$ & $\mathrm{Y}$ & $\mathrm{Y}$ & High \\
7 & Pippo \& Aaltonen 2008 & $\mathrm{Y}$ & $\mathrm{Y}$ & $\mathrm{Y}$ & $\mathrm{Y}$ & $\mathrm{Y}$ & $\mathrm{N}$ & $\mathrm{Y}$ & $\mathrm{Y}$ & $\mathrm{Y}$ & $\mathrm{Y}$ & High \\
8 & Wiersma \& Pedlar 2008 & $\mathrm{Y}$ & $\mathrm{Y}$ & $\mathrm{Y}$ & $\mathrm{Y}$ & $\mathrm{Y}$ & $\mathrm{N}$ & $\mathrm{U}$ & $\mathrm{Y}$ & $\mathrm{Y}$ & $\mathrm{Y}$ & Moderate \\
9 & Hordern \& Street 2007 & $\mathrm{Y}$ & $\mathrm{Y}$ & $\mathrm{Y}$ & $\mathrm{Y}$ & $\mathrm{Y}$ & $\mathrm{N}$ & $\mathrm{U}$ & $\mathrm{Y}$ & $\mathrm{Y}$ & $\mathrm{Y}$ & Moderate \\
10 & Sacks \& Nelson 2007 & $\mathrm{Y}$ & $\mathrm{Y}$ & $\mathrm{Y}$ & $\mathrm{Y}$ & $\mathrm{Y}$ & $\mathrm{N}$ & $\mathrm{Y}$ & $\mathrm{N}$ & $\mathrm{Y}$ & $\mathrm{Y}$ & Moderate \\
11 & Mauleon et al. 2007 & $\mathrm{Y}$ & $\mathrm{Y}$ & $\mathrm{Y}$ & $\mathrm{Y}$ & $\mathrm{Y}$ & $\mathrm{N}$ & $\mathrm{Y}$ & $\mathrm{Y}$ & $\mathrm{Y}$ & $\mathrm{Y}$ & High \\
12 & Ekman 2007 & $\mathrm{U}$ & $\mathrm{U}$ & $\mathrm{U}$ & $\mathrm{Y}$ & $\mathrm{U}$ & $\mathrm{N}$ & $\mathrm{Y}$ & $\mathrm{N}$ & $\mathrm{N}$ & $\mathrm{U}$ & Low \\
13 & Donnelly \&Wiechula 2006 & $\mathrm{Y}$ & $\mathrm{Y}$ & $\mathrm{Y}$ & $\mathrm{Y}$ & $\mathrm{U}$ & $\mathrm{U}$ & $\mathrm{Y}$ & $\mathrm{Y}$ & $\mathrm{Y}$ & $\mathrm{Y}$ & Moderate \\
14 & Brown et al. 2006 & $\mathrm{Y}$ & $\mathrm{Y}$ & $\mathrm{Y}$ & $\mathrm{Y}$ & $\mathrm{Y}$ & $\mathrm{Y}$ & $\mathrm{Y}$ & $\mathrm{Y}$ & $\mathrm{Y}$ & $\mathrm{Y}$ & High \\
15 & Lindgren et al.2006 & $\mathrm{Y}$ & $\mathrm{Y}$ & $\mathrm{Y}$ & $\mathrm{Y}$ & $\mathrm{Y}$ & $\mathrm{Y}$ & $\mathrm{Y}$ & $\mathrm{Y}$ & $\mathrm{Y}$ & $\mathrm{Y}$ & High \\
16 & Leiphart\& Barnes 2005 & $\mathrm{Y}$ & $\mathrm{Y}$ & $\mathrm{Y}$ & $\mathrm{U}$ & $\mathrm{U}$ & $\mathrm{N}$ & $\mathrm{N}$ & $\mathrm{U}$ & $\mathrm{U}$ & $\mathrm{U}$ & Low \\
17 & Langley \& Klopper 2005 & $\mathrm{Y}$ & $\mathrm{Y}$ & $\mathrm{Y}$ & $\mathrm{U}$ & $\mathrm{U}$ & $\mathrm{N}$ & $\mathrm{Y}$ & $\mathrm{U}$ & $\mathrm{Y}$ & $\mathrm{Y}$ & Moderate \\
18 & Thomas et al. 2004 & $\mathrm{Y}$ & $\mathrm{Y}$ & $\mathrm{Y}$ & $\mathrm{Y}$ & $\mathrm{Y}$ & $\mathrm{N}$ & $\mathrm{N}$ & $\mathrm{Y}$ & $\mathrm{Y}$ & $\mathrm{U}$ & Moderate \\
19 & Mok \& Chiu 2004 & $\mathrm{Y}$ & $\mathrm{Y}$ & $\mathrm{Y}$ & $\mathrm{U}$ & $\mathrm{Y}$ & $\mathrm{N}$ & $\mathrm{Y}$ & $\mathrm{Y}$ & $\mathrm{Y}$ & $\mathrm{Y}$ & High \\
20 & Battaglia et al. 2003 & $\mathrm{Y}$ & $\mathrm{Y}$ & $\mathrm{Y}$ & $\mathrm{Y}$ & $\mathrm{Y}$ & $\mathrm{N}$ & $\mathrm{N}$ & $\mathrm{Y}$ & $\mathrm{Y}$ & $\mathrm{Y}$ & High \\
\hline
\end{tabular}

Appendix 2. Example of assessment The Critical Appraisal Skills Program [24], a methodological checklist of key criteria relevant to qualitative studies. (Y: yes, N: no, U: unclear).

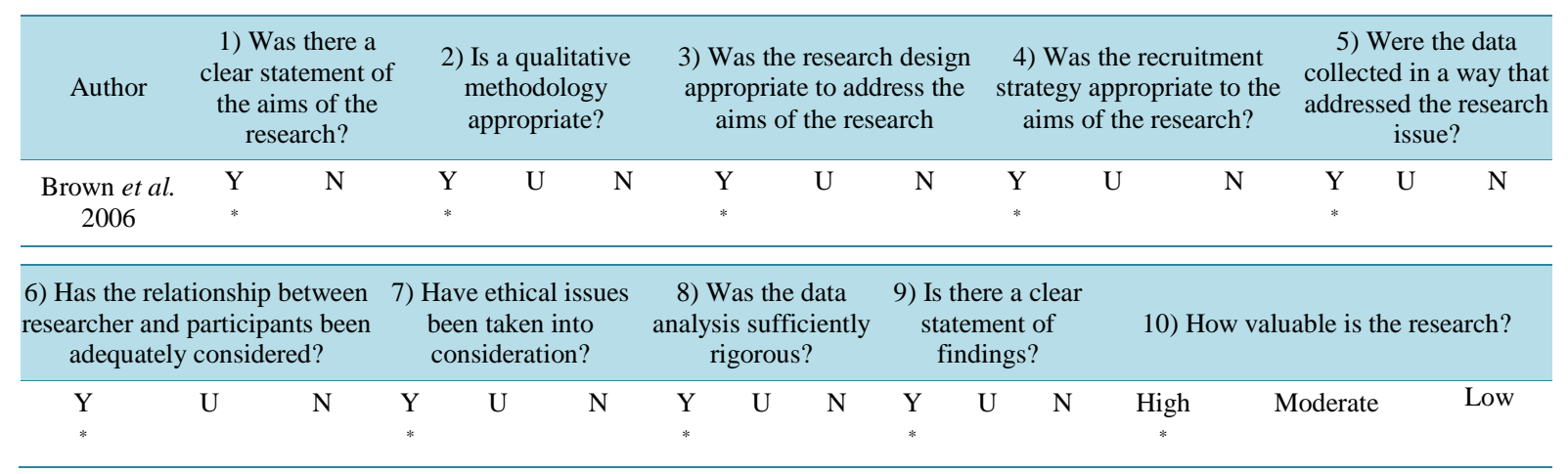

